\title{
AGE-RELATED DIFFERENCES IN FITNESS PERFORMANCE AND TECHNICAL SKILLS OF YOUNG SOCCER PLAYERS
}

\author{
KRZYSZTOF LIPECKI
}

\author{
Cracow University of Economics, Faculty of Management, Department of Tourism, Cracow, Poland
}

Mailing address: Krzysztof Lipecki, Cracow University of Economics, Faculty of Management, Department of Tourism, 27 Rakowicka Street, 31-510 Kraków, tel.: +48 12 2935096, fax: +48 12 2935045, e-mail: lipeckik@uek.krakow.pl

\begin{abstract}
Introduction. The aim of the study was to identify differences in the level of fitness and technical skills of young soccer players depending on age. Material and methods. The study examined 140 male elite soccer players from the Polish Sport Academy aged 12 to 18 years. Body mass, body height, fitness abilities $(5-\mathrm{m}, 10-\mathrm{m}$, and 30-m sprint; envelope run; standing long jump; pull-ups; and beep test) and technical skills (ball handling, juggling alternately with the leg and the head, short passes, and long passes) were measured. Results. Statistically significant $(\mathrm{p}<0.05)$ differences indicating improvement with age were found in older players in speed (15.5\%-18.8\%), agility (5.7\%), lower limb explosive power (39.4\%), upper limb strength (254.3\%), and cardiorespiratory endurance (31.9\%). With regards to technical skills, the greatest progress was documented for long shots (passes) with the internal instep from the ground ( $140.6 \%$ for the dominant leg, DL, and $730.3 \%$ for the non-dominant leg, NDL). Slightly lower results were obtained for short shots (passes) with the central instep from the air (128\% for DL and $103.6 \%$ for NDL) and short shots (passes) with the medial part of the foot (52.1\% for DL and $82.8 \%$ for NDL), and the lowest were recorded for ball handling with direction change (32.3\% for DL and 29.9\% for NDL). Conclusions. In the process of talent identification and monitoring of training effects, coaches should take into account the differences in the rate of the development of fitness and technical skills of young athletes.
\end{abstract}

Key words: speed, agility, strength, technical skills, development

\section{Introduction}

In contemporary soccer, athletes are challenged with increasingly high expectations. During a match, players are exposed to constant pressure by the opponents, and effective play requires a high level of fitness and technical skills. Many studies available in the literature have evaluated fitness-related abilities, with particular focus on the aerobic capacity [1-5], anaerobic capacity [6-10], speed [11-14], agility [15, 16], and muscle strength [17-21] of soccer players with different skill levels. The technical skills of players have also been often explored by researchers all over the world [22-29]. However, most studies have presented the results of small groups of athletes from selected age categories and focused exclusively on fitness [2, 5, 11, 15] or technical skills $[22,24,27,28]$. There has been a gap in the world literature concerning the identification of the levels of both fitness and technical skills of soccer players from different age groups and at different skill levels. Such cross-sectional studies are scarce $[16,23,25,30]$ and seem to have particular cognitive value, since they provide insight into the variability of specific characteristics, and practical value, as they can serve as comparative material for coaches in periodic training monitoring.

The aim of this study was to identify differences in the level of fitness (speed, agility, strength, and cardiorespiratory endurance) and technical skills (ball handling with direction change, shots with the central instep from the air, shots performed low to the ground with the medial part of the foot, and long shots with the internal instep from the ground) of young soccer players aged 12 to 18 years.

\section{Material and methods}

\section{Participants}

The study examined 140 high-level male players from the Polish Sport Academy aged 12 to 18 years. All the study participants were volunteers. Written consent was also obtained from the parents of each child. The examination began with a 20-minute warm-up. The athletes were familiarised with the study aim, and the measurements were performed in the standard environment of an indoor arena.

\section{Anthropometric measurements}

The somatic characteristics of each player were evaluated. Body height was measured using an anthropometer, whereas body mass was evaluated by means of TANITA BC-601 electronic scales. The anthropometric parameters of the players are presented in Table 1.

\section{Evaluation of fitness abilities}

During two training sessions, five fitness components were evaluated. On the first day, the players performed the standing long jump, sprint, and envelope run tests, and on the second day, they did the pull-ups and beep tests. These components were the following:

a) Speed: 5-m sprint, 10-m sprint, and 30-m sprint. Each study participant was asked to run the distance of $30 \mathrm{~m}$ as fast as possible. Using the MICROGATE photocell system (Witty System User Manual - Manual version 1.4), the running time was measured over the distance of 5 metres, 10 metres, and 30 metres with an accuracy of $0.001 \mathrm{~s}$. The start 
Table 1. Study participant characteristics

\begin{tabular}{|c|c|c|c|c|c|c|c|c|c|c|c|}
\hline & & $\begin{array}{c}\text { U12 } \\
N=29\end{array}$ & $\begin{array}{c}\text { U13 } \\
N=17\end{array}$ & $\begin{array}{c}\text { U14 } \\
N=15\end{array}$ & $\begin{array}{c}\text { U15 } \\
N=17\end{array}$ & $\begin{array}{c}\text { U16 } \\
N=25\end{array}$ & $\begin{array}{c}\text { U17 } \\
N=21\end{array}$ & $\begin{array}{c}\text { U18 } \\
N=16\end{array}$ & & & \\
\hline Variable & & & & & & & & & $F$ & $p$ & $\eta_{p}^{2}$ \\
\hline Body mass $[\mathrm{kg}]$ & $\begin{array}{c}X \\
\pm S D\end{array}$ & $\begin{array}{l}40.5 \\
6.69\end{array}$ & $\begin{array}{l}45.5 \\
8.95\end{array}$ & $\begin{array}{l}54.7 \\
9.80\end{array}$ & $\begin{array}{l}57.8 \\
8.14\end{array}$ & $\begin{array}{l}63.7 \\
7.17\end{array}$ & $\begin{array}{l}68.1 \\
7.57\end{array}$ & $\begin{array}{l}71.4 \\
6.58\end{array}$ & 1031.1 & 0.00 & 0.416 \\
\hline $\begin{array}{l}\text { Body height } \\
{[\mathrm{cm}]}\end{array}$ & $\begin{array}{c}X \\
\pm S D \\
\end{array}$ & $\begin{array}{c}149.9 \\
7.90 \\
\end{array}$ & $\begin{array}{c}156.5 \\
9.51 \\
\end{array}$ & $\begin{array}{c}164.3 \\
8.55 \\
\end{array}$ & $\begin{array}{c}171.2 \\
9.17 \\
\end{array}$ & $\begin{array}{c}173.3 \\
7.69 \\
\end{array}$ & $\begin{array}{c}178.7 \\
7.04 \\
\end{array}$ & $\begin{array}{c}179.0 \\
6.85 \\
\end{array}$ & 7945.1 & 0.00 & 0.416 \\
\hline $\begin{array}{c}\text { BMI } \\
{\left[\mathrm{kg} / \mathrm{m}^{2}\right]}\end{array}$ & $\begin{array}{c}X \\
\pm S D\end{array}$ & $\begin{array}{l}17.9 \\
1.82\end{array}$ & $\begin{array}{l}18.4 \\
1.82\end{array}$ & $\begin{array}{l}20.1 \\
2.39\end{array}$ & $\begin{array}{l}19.6 \\
1.45\end{array}$ & $\begin{array}{l}21.1 \\
1.51\end{array}$ & $\begin{array}{l}21.3 \\
1.47\end{array}$ & $\begin{array}{l}22.1 \\
1.42\end{array}$ & 2553.4 & 0.00 & 0.416 \\
\hline $\begin{array}{l}\text { Right and left } \\
\text { leg dominant } \\
\text { percentage }\end{array}$ & $\mathrm{R}$ & $\begin{array}{l}86.20 \\
13.80\end{array}$ & $\begin{array}{l}88.20 \\
11.80\end{array}$ & $\begin{array}{l}80.00 \\
20.00\end{array}$ & $\begin{array}{l}82.35 \\
17.64\end{array}$ & $\begin{array}{l}84.00 \\
16.00\end{array}$ & $\begin{array}{l}85.71 \\
14.28\end{array}$ & $\begin{array}{l}87.50 \\
12.50\end{array}$ & --- & --- & --- \\
\hline
\end{tabular}

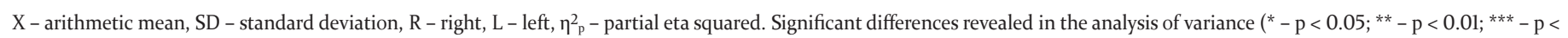
0.001 ) between individual age groups for particular variables are given below.

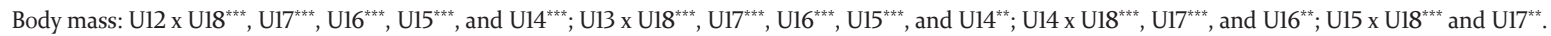

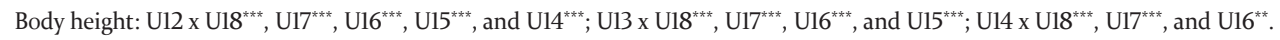

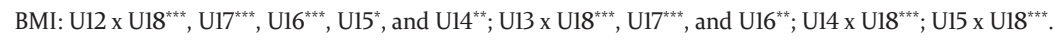

line was coincident with the line of the first photocell gate, whereas other gates were located at the distances of 5, 10, and 30 metres. The players performed a standing start three times with 3-minute rest intervals. Further analysis was based on the best results obtained for each distance.

b) Agility: envelope run $(5 \times 3 \mathrm{~m})$ [31]. The players ran 3 laps of the specified route (Fig. 1). Running time was measured using the MICROGATE photocell system (Witty System User Manual - Manual version 1.4) with an accuracy of $0.001 \mathrm{~s}$. The start line with the photocell gate was located at a distance of 2 metres from the A point at the extension of the $\mathrm{B}-\mathrm{A}$ line. The start/finish gate width was 3 metres. The players performed a standing start two times with 3-minute rest intervals. Further analysis was based on the best results over two trials.

c) Lower limb explosive power: standing long jump [31]. Further analysis was based on the best results over three trials.

d) Upper limb strength: pull-ups [32]. The number of completed pull-ups was counted (a pull-up was completed with lowering of the body until the arms were fully extended in the bottom hanging position).

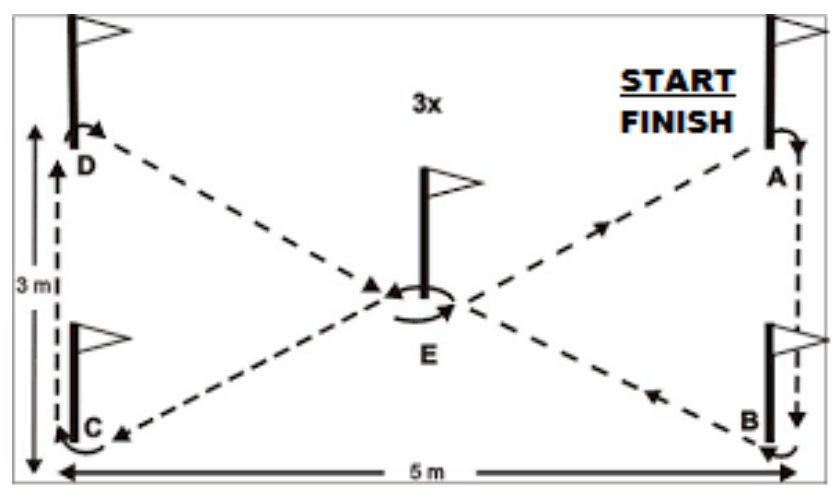

Legend:

------- - runners' route (A-B-E-C-D-E). e) Cardiorespiratory endurance: beep test [31]. The run time was measured.

\section{Evaluation of technical skills}

Technical skills were evaluated using motor skills tests to diagnose the following parameters [33]:

a) Speed of ball handling with direction change: dribbling the ball between uprights with a change of direction. The player was asked to dribble the ball on a specified route (slalom between poles) using only one leg (DL and NDL). The player performed two tests for each leg, and further analysis concerned the better result for DL and NDL.

b) Accuracy of short shots (passes) performed with the central instep from the air: juggling alternately with the foot and the head. The number of foot-head cycles performed by a player within $30 \mathrm{~s}$ with only one leg was counted. The better result of the two tests was recorded separately for DL and NDL.

c) Effectiveness of short shots (passes) low to the ground using the medial part of the foot: shots on bench performed low to the ground with the medial part of the foot test. The number of goals (points) scored by the player using shots performed low to the ground with the medial part of the foot from the distance of $6 \mathrm{~m}$ in $90 \mathrm{~s}$. Further analysis concerned the better results of the two tests, recorded separately for the DL and NDL.

d) Effectiveness of long shots (passes) performed using the internal instep from the ground: $20-\mathrm{m}$ internal instep shots on goal from the ground. After an approach run, the player performed 20 shots (10 with DL and 10 with NDL alternately) from the ground using the internal instep at the goal. The goal $(3 \mathrm{~m} \times 2 \mathrm{~m})$ was divided into two parts with a tape (attached $1 \mathrm{~m}$ from the ground), and the player scored 3 points if the ball went on target (the upper part) and 1 point when it went to the lower part. Scores were not counted if the ball bounced from the ground before reaching the goal. The result was represented by the total points scored in 10 shots, separately for DL and NDL.

Figure 1. Envelope run route 


\section{Data analysis}

STATISTICA 12 PL software was used for the statistical analysis of the data. Distribution was analysed in groups and subgroups based on the Shapiro-Wilk test (for $n<100$ ). Basic measures (i.e. percentage distribution, means, standard deviations, confidence intervals, and coefficients of variation) were computed. Statistical hypotheses were tested between players stratified by age group using one-way analysis of variance (ANOVA) and Tukey's post-hoc test. A level of significance of $5 \%$ was adopted. Corrected p-values and effect sizes estimated using partial Eta squared $\left(\eta^{2}\right)$ for ANOVAs and Cohen's $d$ for t-tests are reported.

\section{Results}

The analysis of the somatic parameters of soccer players aged from 12 to 18 years revealed substantial differences in body mass, body height, and BMI. The differences between individual categories (U12 and U18) amounted to 4.6\%-16.8\% for body height, $0.1 \%-4.6 \%$ for body mass, and 0.8\%-8.4\% for BMI (Tab. 1).

The analysis of the level of fitness abilities revealed statistically significant differences between individual groups of players (U12-U18) in 5-m sprint, 10-m sprint, and 30-m sprint (Tab. 2 ). The results showed that older players improved their results compared to younger players by $1.0 \%-5.0 \%$, with the differences between the U18 and U12 groups maintained at a similar level (ca. 20.0\%) for each distance (5 m, 10 m, and $30 \mathrm{~m}$ ). Substantially lower differences between the groups were observed for agility $(0.5 \%-2.5 \%)$, with statistically significantly better results obtained by older players (U18, U17, and U16) compared to the participants from the U12 group. Differences in explosive strength of lower limbs evaluated in the standing long jump tests decreased with age, from $9.9 \%$ between U13 and U12 to $0.9 \%$ between U18 and U17. A similar pattern was documented for upper limb strength. However, the differences were substantially greater and ranged from $67.5 \%$ between U15 and U14 to $12.9 \%$ between U18 and U17. Despite substantial differences, the U18 group were found to be statistically significantly stronger compared to U14 ( $<<0.05)$, whereas in other cases, the differences were statistically insignificant $(\mathrm{p}>0.05)$. As for cardiorespiratory endurance, the study revealed statistically significantly better results (by $11.0 \%-13.4 \%, \mathrm{p}<0.05$ ) in older players for the comparisons between U15 and U16, U16 and U17, as well as between U16 and U18.

When it comes to the subjects' technical skills, the results of ball handling with direction change differed significantly between players from the age groups examined (Fig. 2). Differences of ca. 30.0\% ( $<$ < 0.05) were found between the groups U12 and U18 in the case of the test performed with the dominant leg (DL) and between the groups U12 and U15 for the nondominant leg (NDL). The results for juggling alternately with the foot and the head revealed significant differences $(56.3 \%$, $\mathrm{p}<0.05$ ) for the dominant leg between the U13 and U18 groups

Table 2. Differences in fitness level of soccer players aged from 12 to 18 years (U12-U18)

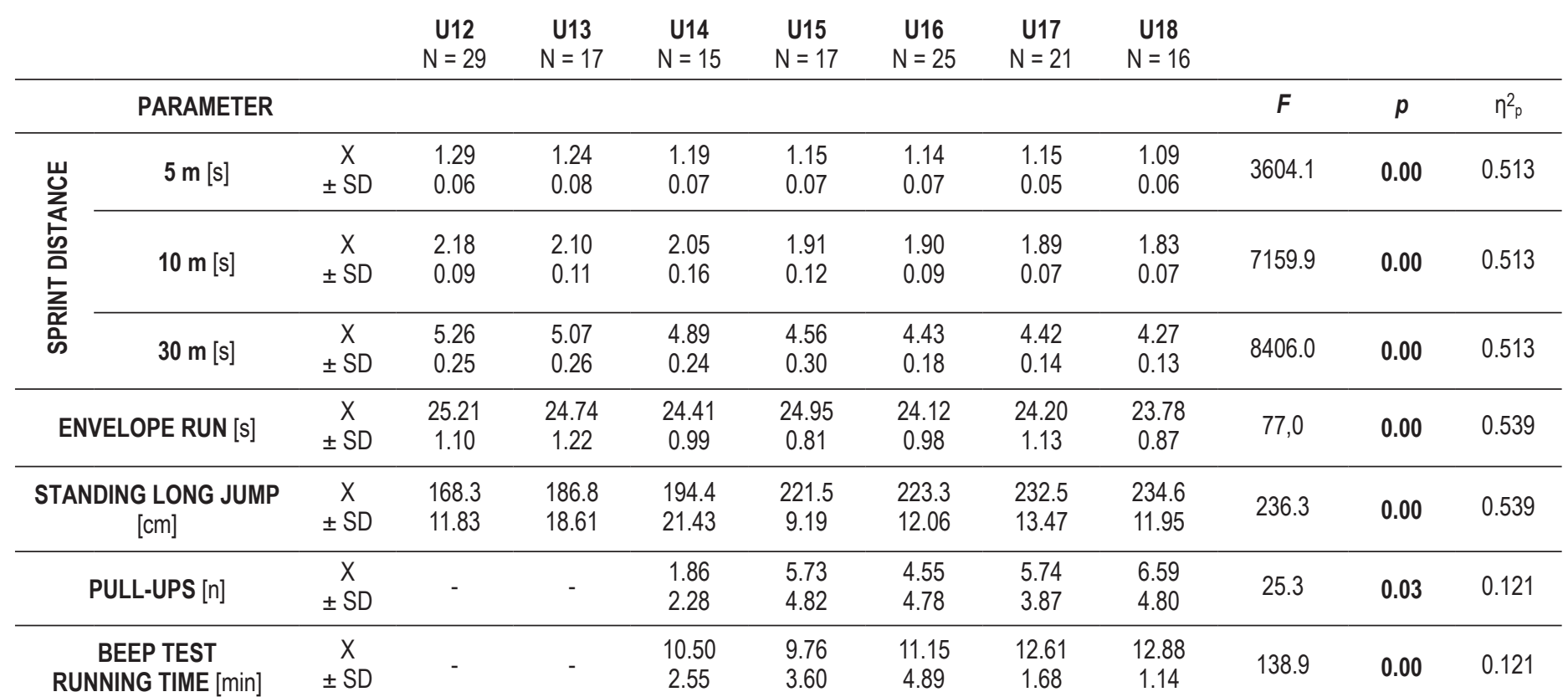

$\mathrm{X}$ - arithmetic mean, SD - standard deviation, $\eta_{\mathrm{p}}^{2}$ - partial eta squared. Significant differences revealed in the analysis of variance $\left(^{*}-\mathrm{p}<0.05\right.$; ${ }^{* *}-\mathrm{p}<0.01$; $\left.{ }^{* *}-\mathrm{p}<0.001\right)$ between individual age groups for particular variables are given below.

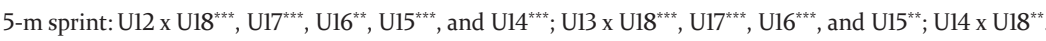

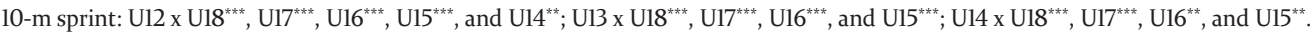

30-m sprint: U12 x U18 ${ }^{* * *}, \mathrm{Ul}^{* * *}, \mathrm{U16} 6^{* *}, \mathrm{U1} 5^{* * *}$, and U14 ${ }^{* * *}$; U13 x U18 ${ }^{* * *}, \mathrm{U1}{ }^{* * *}, \mathrm{U1} 6^{* * *}$, and U15 ${ }^{* * *}$; U14 x U18 ${ }^{* * *}$, U17 ${ }^{* * *}$, U16 ${ }^{* * *}$, and U15 $5^{* *}$; U15 x U18

Envelope run: U12 x U18 $8^{* *}, \mathrm{U17} 7^{*}$, and U16*.

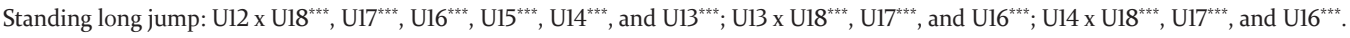

Pull-ups: U14 x U18*.

Beep test: U16 x U18 ${ }^{* * *}$, U17 ${ }^{* * *}$, and U15 ${ }^{* * *}$. 
(with better results found in older players), whereas in the case of the non-dominant leg, differences were found between older groups (U18, U17, and U16) and players from the youngest groups (U14, U13, and U12; 42.4\%-103.0\% at p < 0.05). Statistically significant differences were observed between younger groups (U12, U13, and U14) and older groups (U17 and U18) during shots on bench performed low to the ground with the medial part of the foot. In the case of the test performed with the dominant leg, older players performed better by $31.0 \%-52.0 \%$ $(\mathrm{p}<0.05)$, whereas in the test with the non-dominant leg, the results were better by $25.6 \%-79.6 \%(\mathrm{p}<0.05)$ compared to younger players. Even greater differences were documented for 20-m internal instep shots on goal performed from the ground. For the dominant leg, U15-U18 players scored better $(\mathrm{p}<0.05)$ compared to U14 (by ca. 55.0\%), U13 (by ca. 70.0\%), and U12 (by ca. 120.0\%). The results for the non-dominant leg showed even greater differences, of ca. 130.0\% compared to U14, 725.0\% compared to U13, and 500.0\% compared to U12. An analysis of the total results obtained for the dominant and non-dominant leg in this test showed that the players from the U18 and U15 groups had better mean results (by 75.0\%-187.7\%) compared to younger players (U14, U13, and U12).

The study found statistically significant differences between age groups, with older players showing better speed $(15.5 \%$ $18.8 \%$ difference between U12 and U18 players, $\mathrm{p}<0.001)$, agility $(5.7 \%, \mathrm{p}<0.001)$, explosive power of lower limbs $(39.4 \%$, $\mathrm{p}<0.001)$, upper limb strength (254.3\% difference between U14 and U18, p < 0.05) and cardiorespiratory endurance $(31.9 \%$ difference between U15 and U18, $\mathrm{p}<0.001)$. With regards to technical skills, the players' results improved in all the tests, with different results obtained for each skill. The greatest differences were documented for long passes with the internal instep from the ground; the results improved between U12 and U15 by $140.6 \%\left(\mathrm{p}<0.001, \eta_{\mathrm{p}}^{2}=0.322\right)$ for the dominant leg (DL) and by $730.3 \%\left(p<0.001, \eta_{p}^{2}=0.322\right)$ between U13 and U17 for the non-dominant leg (NDL). Slightly lower results were obtained
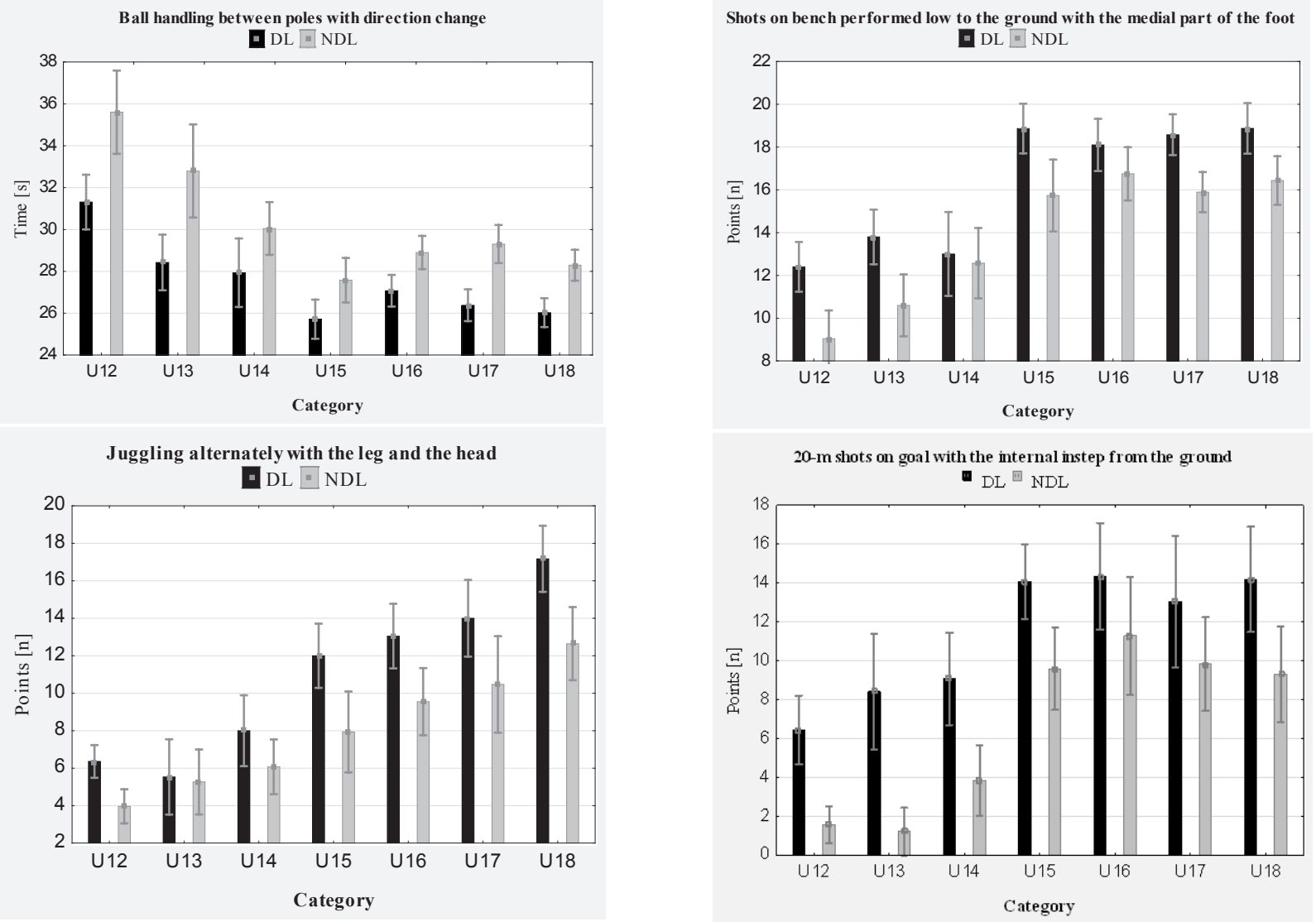

DL - dominant leg, NDL - non-dominant leg. Significant differences revealed in the analysis of variance $(*-p<0.05$; ** $-\mathrm{p}<0.01$; *** $-\mathrm{p}<0.001)$ between individual age groups for particular variables are given below.

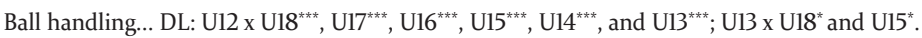

Ball handling... NDL: U12 x U18 ${ }^{* * *}, \mathrm{Ul}^{* * *}, \mathrm{U16}{ }^{* * *}, \mathrm{U1} 5^{* * *}$, and U14 ${ }^{* * *}$; U13 x U18 ${ }^{* *}, \mathrm{Ul}^{* *}, \mathrm{U1}^{* *}$, and U15 ${ }^{* * *}$.

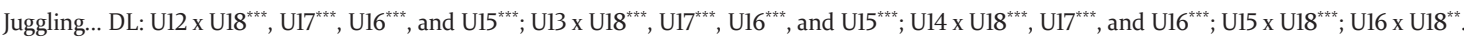

Juggling... NDL: U12 x U18 $8^{* * *}$, U17 ${ }^{* * *}$, and U16 ${ }^{* * *}$; U13 x U18 $8^{* * *}$, U17 ${ }^{* *}$, and U16 $6^{*}$ U14 x U18 $8^{* * *}$ and U17* U15 x U18**.

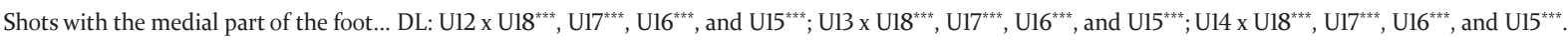

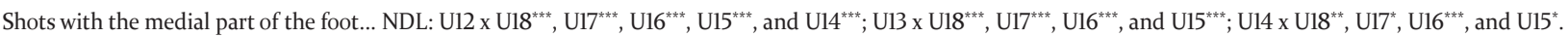

Shots with the internal instep... DL: U12 x U18 ${ }^{* * *}, \mathrm{Ul}^{* *}, \mathrm{U16}{ }^{* * *}$, and U15 $5^{* * *}$; U13 x U18 ${ }^{*}$ and U16.

Shots with the internal instep... NDL: U12 x U18 ${ }^{* * *}$, U17 ${ }^{* * *}, \mathrm{U16}{ }^{* * *}$, and U15 ${ }^{* * *}$; U13 x U18 ${ }^{* * *}$, U17 $7^{* * *}$, U16 ${ }^{* * *}$, and U15 $5^{* * *}$; U14 x U18

Shots with the internal instep... TOTAL: U12 x U18 ${ }^{* * *}$, U17 ${ }^{* * *}, \mathrm{Ul}^{* * *}$, and U15 ${ }^{* * *}$; U13 x U18 ${ }^{* * *}$, U17 ${ }^{* * *}$, U16 ${ }^{* * *}$, and U15 ${ }^{* * *}$; U14 x U18*, U17 ${ }^{* *}$, U16 ${ }^{* * *}$, and U15 ${ }^{* *}$.

Figure 2. Mean results obtained by football players aged from 12 to 18 years in technical skill tests 
for the following: short shots with the central instep from the air, as there was improvement between U13 and U18 of 128\% $\left(\mathrm{p}<0.001, \eta^{2} \mathrm{p}=0.347\right)$ for DL and of $103.6 \%$ between U12 and U18 ( $\left.p<0.001, \eta^{2}{ }_{p}=0.347\right)$ for NDL; short shots with the medial part of the foot, with improvement between U12 and U18 of $52.1 \%$ for DL and $82.8 \%$ for NDL $\left(\mathrm{p}<0.001, \eta^{2}=0.347\right)$; and ball handling with direction change (lowest improvement), with the results differing between U12 and U18 by 32.3\% for DL and $29.9 \%$ for NDL $\left(\mathrm{p}<0.001, \eta_{\mathrm{p}}^{2}=0.347\right)$.

\section{Discussion}

The aim of the study was to identify differences in the level of fitness and technical skills of soccer players aged 12 to 18 years. An analysis of the differences between the groups revealed improvements in speed, agility, muscle strength, and cardiovascular endurance. The improvement of the results achieved in terms of physical fitness abilities, resulting from the biological development and participation in sport-specific soccer training [34], was also found in French [35], Hungarian [36], Spanish [29], Brazilian [30], and Dutch [23] soccer players of various ages (U9-U18). The results of our study showed a tendency for the differences between most physical fitness components (speed, agility, and explosive strength of lower limbs) to decrease with age between the athletes from the two closest categories. Insignificant differences between U18 and U17 players in speed (from $3.2 \%$ to $5.2 \%$ depending on the distance of $5 \mathrm{~m}, 10 \mathrm{~m}$ and $30 \mathrm{~m})$, cardiorespiratory endurance (2.1\%), agility (1.7\%), and explosive strength of the lower limbs (0.9\%) might suggest that the athletes from the oldest categories were near their maximum performance and that the scope of changes in older age will be limited. The reserves seem to lie in upper limb strength, where the difference between the results of the oldest groups was $12.9 \%$ and indicated substantial opportunities for the development of this ability in players over 18 years of age.

A comparison of mean results obtained by Polish soccer players in this study with elite-level peers all over the world shows that they had slightly worse results than their Hungarian peers [36] in speed (5-m, 10-m, and 30-m sprint), similar or higher explosive strength of the lower limbs compared to athletes from Hungary and Belgium [34, 36], and a higher level of cardiovascular endurance compared to Belgian and Slovenian soccer players $[2,34]$.

With regard to the level of technical skills of soccer players aged from 12 to 18 years, the athletes improved their results in all tests as they got older. Apart from the improvement of the results, regardless of the ability tested (ball handling, short passes with the central instep or medial part of the foot, or long passing with the internal instep) and the leg (dominant or nondominant), periods of relative stabilisation or even regression can be noticed (Fig. 2). The first of them occurred at the age between 13 and 14 years, whereas the other one was observed between 15 and 16 years of age. With regards to the ability to perform short shots (passes) with the central instep from the air and accurate and quick short shots (passes) performed low to the ground with the medial part of the foot, U14 players had worse results compared to U13 players for the dominant leg (by $11.7 \%$ and $7.2 \%$, respectively) and slightly better results for the non-dominant leg (by $1.5 \%$ and $13.1 \%$, respectively). Worse results were obtained by 13 -year-old players compared to 12 -yearolds in ball handling with direction change were also found by Gonçalves et al. [28] in a group of Brazilian players. Stabilisation or deterioration in the results in this age range was observed in a long-term study of Polish soccer players as well [37]. This is likely to be due to puberty and the related disturbances in the abilities to control and regulate complex coordinated movements [38].

The second period of relative stabilisation is reflected by the results obtained by U15 and U16 players. U16 players had worse results in quick and accurate ball handling with direction change (by $9.6 \%$ for DL and $7.3 \%$ for NDL), accuracy of short shots (passes) with the central instep form the air (by $3.8 \%$ for DL and 2.3\% for NDL), accurate and quick short shots (passes) performed low to the ground with the medial part of the foot (by $10.1 \%$ for DL and $1.8 \%$ for NDL) and accurate long shots (passes) with the internal instep from the ground (by $8.6 \%$ for DL). Stabilisation in the development of technical skills was also found in Belgian soccer players aged from 15 to 16 years for ball handling with direction change and performing short passes on goal (no differences were found between the groups) [34], Dutch and Brazilian players for ball handling with direction change [23, 30], and Spanish players (between the ages of 16 and 17 years) for ball handling (improvement by only $0.2 \%$ ) and short shots with the central instep from the air (juggling) (decline by $18.0 \%$ ) [29]. According to experts, the lack of improvement in selected technical skills (mainly ball handling) in soccer players at this age may result from a different speed of biological growth in the final period of adolescence [30]. Soccer player coaches should be aware of a possible effect of adolescence on the results of athletes under 16 years of age. The athletes in more advanced stages of development can be characterised by more favourable somatic parameters and better technical skills. It is important that persons who coach young soccer players understand the temporary character of these benefits of the adolescence and not eliminate athletes who demonstrate a slower rate of biological development.

In conclusion, it should be emphasised that the results presented have practical value, because they indicate tendencies in the development of football-related fitness abilities and technical skills among young players following the same training system, and the fairly wide range of tests allows a comparison of the current findings against the results of players of other football academies. Due to the fact that in the world literature, there is little data on the level of fitness or technical skills of young Polish football players (there are results concerning young footballers from Brazil, Spain, or Belgium), the current research can be valuable comparative material.

The present study has some limitations. One of them is that the results have a cross-sectional character and concern a number of age groups with a relatively small size. Therefore, it is necessary to ensure due diligence when drawing conclusions, which should reveal the major tendencies rather than the differences between the two closest groups. The results concern male elite soccer players. Therefore, they should not be referred to female athletes and athletes at other skill levels.

\section{Conclusions}

The fitness and technical skills of young soccer players aged 12 to 18 are characterised by a varied rate of development. Steady improvements in the results were observed for anthropometric parameters (body height and mass), fitness abilities (speed, agility, strength of lower and upper limbs, and cardiorespiratory endurance), whereas periods of relative stabilisation (or regression) in technical skills (ball handling with direction change, kicking the ball with the central instep from the air, and kicking the ball low to the ground with the medial part of the foot) were found between players aged 13 and 14 years and between those 
aged 15 and 16 years. In light of the above findings, the coaches responsible for the recruitment and monitoring of training effects should take into account the varied rate of the development of fitness and technical skills of young athletes.

\section{Acknowledgements}

The study was funded from resources supporting research conducted by young researchers allocated to the Faculty of Management of the Cracow University of Economics, Poland, by the Polish Ministry of Science and Higher Education.

\section{Literature}

1. Andrzejewski M., Chmura J., Dybek T., Pluta B. (2012). Sport exercise capacity of soccer players at different levels of performance. Biology of Sport 29(3), 185-191.

2. Kavcic I., Milic R., Jourkesh M., Ostojic S.M., Ozkol M.Z. (2012). Comparative study of measured and predicted VO2max during a multi-stage fitness test with junior soccer players. Kinesiology 44(1), 18-23.

3. Helgerud J., Engen L.C., Wisloff U., Hoff J. (2001). Aerobic endurance training improves soccer performance. Medicine and Science in Sports and Exercise 33(11), 1925-1931.

4. Roescher C.R., Elferink-Gemser M.T., Huijgen B.C.H., Visscher C. (2010). Soccer endurance development in professionals. International Journal of Sports Medicine 31, 174179.

5. Jones R.M., Cook C.C., Kilduff L.P., Milanović Z., James N., Sporiš G. at al. (2013). Relationship between repeated sprint ability and aerobic capacity in professional soccer players. Science World Journal 952350.

6. Buzolin N.O., Barbieri F.A., Barbieri R.A., Gobbi L.T.B. (2009). Agility, speed and motor skill performance of practitioners and non-practitioners of soccer. Fitness $\mathcal{E}$ Performance 8(2), 110-4.

7. Moro V.L., Fuke K., Cancian L., Matheus S.C., Moro A.R. (2012). Anaerobic capacity in soccer players from different competitive levels: Comparison of players in different field positions. Journal Motricidade 8(3), 71-80.

8. Camille T., Plowman S.A., Marilyn L.A. (2002). Reliability and validity of the anaerobic speed test and the field anaerobic shuttle test for measuring anaerobic work capacity in soccer players. Measurement in Physical Education and Exercise Science 6(3), 187-205.

9. Luca A., Sergio O., Marco P., Mura R., Marongiu E., Silvana R. et al. (2012). Aerobic and anaerobic capacity of adult and young professional soccer players. Sport Sciences for Health 8(2/3), 95-100.

10. Tønnessen E., Shalfawi S.A., Haugen T., Enoksen E. (2011). The effect of 40-m repeated sprint training on maximum sprinting speed, repeated sprint speed endurance, vertical jump, and aerobic capacity in young elite male soccer players. The Journal of Strength and Conditioning Research 25(9), 2364-70.

11. Mujika I., Spencer M., Santisteban J., Goiriena J.J., Bishop D. (2009). Age-related differences in repeated-sprint ability in highly trained youth football players. Journal of Sports Sciences 27(14), 1581-90.

12. Mendez-Villanueva A., Buchheit M., Kuitunen S., Douglas A., Peltola E., Bourdon P. (2011). Age-related differences in acceleration, maximum running speed, and repeated-sprint performance in young soccer players. Journal of Sports Sciences 29(5), 477-84.
13. Mathisen G., Pettersen S.A. (2015). Anthropometric factors related to sprint and agility performance in young male soccer players. Journal of Sports Medicine 5(6), 337-42.

14. Köklü Y., Alemdaroğlu U., Özkan A., Koz M., Ersöz G. (2015). The relationship between sprint ability, agility and vertical jump performance in young soccer players. Science E Sports 30(1), 1-5.

15. Erikoglu O.G., Arslan E. (2016). The relationships among acceleration, agility, sprinting ability, speed dribbling ability and vertical jump ability in 14-year-old soccer players. Journal of Sports and Physical Education 3(2), 29-34.

16. Ozan S., Erkal A. (2016). Agility, acceleration, speed and maximum speed relationship with age factor in soccer players. Journal of Human Sciences 13(3), 5560-5667.

17. Comfort P., Stewart A., Bloom L., Clarkson B. (2014). Relationships between strength, sprint, and jump performance in well-trained youth soccer players. The Journal of Strength and Conditioning Research 28(1), 173-7.

18. Dello I.A., Padulo J., Ayalon M. (2016). Core stability training on lower limb balance strength. Journal of Sports Sciences 34(7), 671-678.

19. Di Giminiani R., Visca C. (2017). Explosive strength and endurance adaptations in young elite soccer players during two soccer seasons. PLoS One 12(2), 0171734.

20. Peñailillo L., Espíldora F., Jannas-Vela S., Mujika I., Zbinden-Foncea H. (2016). Muscle strength and speed performance in youth soccer players. Journal of Human Kinetics 50, 203-210.

21. Maly T., Zahalka F., Mala L. (2016). Unilateral and ipsilateral strength asymmetries in elite youth soccer players with respect to muscle group and limb dominance. International Journal of Morphology 34(4), 1339-1344.

22. Joo C.H., Seo D.I. (2016). Analysis of physical fitness and technical skills of youth soccer players according to playing position. Journal of Exercise Rehabilitation 12(6), 548-552.

23. Huijgen B.C., Elferink-Gemser M.T., Post W., Visscher C. (2010). Development of dribbling in talented youth soccer players aged 12-19 years: A longitudinal study. Journal of Sports Sciences 28(7), 689-98.

24. Duarte J.P., Tavares Ó., Valente-dos-Santos J., Severino V., Ahmed A., Rebelo-Gonçalves R. et al. (2016). Repeated dribbling ability in young soccer players: Reproducibility and variation by the competitive level. Journal of Human Kinetics 53, 155-166.

25. Massimo F.F., Figueiredo A.J., Terribili M., Tessitore A. (2016). Analysis of the intraseasonal stability of field test performances in young academy soccer players. Journal of Sports Sciences 34(10), 966-972.

26. Zago M., Piovan A.G., Annoni I., Ciprandi D., Iaia F.M., Sforza C. (2016). Dribbling determinants in sub-elite youth soccer players. Journal of Sports Sciences 34(5), 411-419.

27. Sáez de Villarreal E., Suarez-Arrones L., Requena B., Haff G.G., Ferrete C. (2015). Effects of plyometric and sprint training on physical and technical skill performance in adolescent soccer players. The Journal of Strength and Conditioning Research 29(7), 1894-903.

28. Gonçalves L.G.C., Aquino R.L.T., Filho H.T., Puggina E.F. (2016). Profile characterization of young soccer players: An analysis of the technical skills and anthropometric variables. Journal Motricidade 12(2), 27-37.

29. Fernandez-Gonzalo R., De Souza-Teixeira F., Bresciani G., García-López D., Hernández-Murúa J.A., JiménezJiménez R. et al. (2010). Comparison of technical and physiological characteristics of prepubescent soccer players of 
different ages. The Journal of Strength and Conditioning Research 24(7), 1790-8.

30. Matta M.O., Figueiredo A.J.B., Garcia E.S., TeixeiraSeabra A.E.T. (2014). Morphological, maturational, functional and technical profile of young Brazilian soccer players. Brazilian Journal of Kinanthropometry and Human Performance 16(3), 277-287.

31. Council of Europe. (1998). Eurofit: Handbook for the EUROFIT tests of physical fitness. Rome.

32. Stratton G., Reilly T., Richardson D., Williams A.M. (2004). Youth soccer: From science to performance. London: Routledge.

33. Witkowski Z., Ljach W. (2006). Tests to evaluate the special technical preparation of football players in the aspect of motion symmetry. Trener 2, 5-9. [in Polish]

34. Vaeyens R., Malina R.M., Janssens M., Van Renterghem B., Bourgois J., Vrijens J. et al. (2006). A multidisciplinary se- lection model for youth soccer: The Ghent Youth Soccer Project. British Journal of Sports Medicine 40(11), 928-934.

35. Le Gall F., Carling C., Williams M., Reilly T. (2010). Anthropometric and fitness characteristics of international, professional and amateur male graduate soccer players from an elite youth academy. Journal of Science and Medicine in Sport 13(1), 90-5.

36. Zalai D., Bobak P., Csaki I., Hamar P., Myrer J.W., Mitchell U.H. et al. (2015). Motor skills, anthropometrical characteristics and functional movement in elite young soccer players. Journal of Exercise, Sports E Orthopedics 2(1), 1-7.

37. Ljach W., Witkowski Z. (2004). Coordination motor abilities in football. Warsaw: COS. [in Polish]

38. Hirtz P. (1985). Coordination skills in school sports. Berlin: Volk und Wissen. [in German]

Submitted: February 20, 2018

Accepted: September 30, 2018 